\title{
PROPOSAL FOR DUAL PRESSURIZED LIGHT WATER REACTOR UNIT PRODUCING 2000 MWE
}

\author{
KYOUNG MIN KANG, SANG WOO NOH and KUNE YULL SUH* \\ Seoul National University \\ 599, Gwanak-Ro, Gwanak-Gu, Seoul, 151-744, Korea \\ *Corresponding author. E-mail : kysuh@snu.ac.kr
}

Received September 23, 2009

The Dual Unit Optimizer 2000 MWe (DUO2000) is put forward as a new design concept for large power nuclear plants to cope with economic and safety challenges facing the $21^{\text {st }}$ century green and sustainable energy industry. DUO2000 is home to two nuclear steam supply systems (NSSSs) of the Optimized Power Reactor 1000 MWe (OPR1000)-like pressurized water reactor (PWR) in single containment so as to double the capacity of the plant. The idea behind DUO may as well be extended to combining any number of NSSSs of PWRs or pressurized heavy water reactors (PHWRs), or even boiling water reactors (BWRs). Once proven in water reactors, the technology may even be expanded to gas cooled, liquid metal cooled, and molten salt cooled reactors. With its in-vessel retention external reactor vessel cooling (IVR-ERVC) as severe accident management strategy, DUO can not only put the single most querulous PWR safety issue to an end, but also pave the way to very promising large power capacity while dispensing with the huge redesigning cost for Generation III+ nuclear systems. Five prototypes are presented for the DUO2000, and their respective advantages and drawbacks are considered. The strengths include, but are not necessarily limited to, reducing the cost of construction by decreasing the number of containment buildings from two to one, minimizing the cost of NSSS and control systems by sharing between the dual units, and lessening the maintenance cost by uniting the NSSS, just to name the few. The latent threats are discussed as well.

KEYWORDS : Dual Units, NSSS, PWR, PHWR, BWR, IVR-ERVC

\section{INTRODUCTION}

The reduction of the cost of electricity produced by nuclear power plants (NPP) has become more compelling than ever over the last few years as a way to cope with the rising oil price. One means to achieve this goal has been to look toward increasing the capacity of NPPs, a global trend in nuclear engineering for the $21^{\text {st }}$ century. In particular, to reduce construction as well as generation cost countries having high population density and vigorous industry have developed designs for larger NPPs such as the Advanced Plant $1000 \mathrm{MWe}$ (AP1000) [1], the Optimized Power Reactor 1000 MWe (OPR1000) [2], the Advanced Power Reactor 1400 MWe (APR1400) [3], the Evolutionary Pressurized Reactor 1600 MWe (EPR1600) [4], and the Advanced Pressurized Water Reactor 1700 MWe (APWR1700) [5], just to name the few. Quite recently the Advanced Power Reactor Plus (APR+) has evolved from the APR 1400 to produce $1500 \mathrm{MWe}$ by increasing the size of the core. The APR+ promises to excel in both economics and safety in the world NPP marketplace. However, expanding the NPP capacity comes understandably at the cost of economics and safety. Large and larger NPPs will tend to necessitate redesign, new manufacturing facilities, and, in more cases than not, resolution of wouldbe licensing issues. For instance, the in-vessel retention external reactor vessel cooling (IVR-ERVC) [6,7] by reactor cavity flooding is one of the key severe accident management strategies adopted by some operating NPPs. As a matter of fact, the Shin-Gori Units 3 and 4 of the APR1400 under construction have recently adopted this strategy. Albeit the IVR-ERVC is considered to be a promising safety strategy for NPPs up to and including $1500 \mathrm{MWe}$, it is rather uncertain at the moment if this strategy will be applied to larger power NPPs.

The Dual Unit Optimizer 2000 MWe (DUO2000) is proposed as an engineered solution to these very challenges. The design concept of the DUO2000 is anchored to combine pressurized water reactor (PWR) units, each generating $1000 \mathrm{MWe}$, in order to produce a total of $2000 \mathrm{MWe}$. The DUO2000 comprises two nuclear steam supply systems (NSSSs) of the OPR 1000 as reference reactor to double the reactor power. Since DUO2000 has naturally evolved from an existing PWR, it is expected that most of the current design engineering, including the IVR-ERVC, may be straightforwardly extrapolated and maintained. 

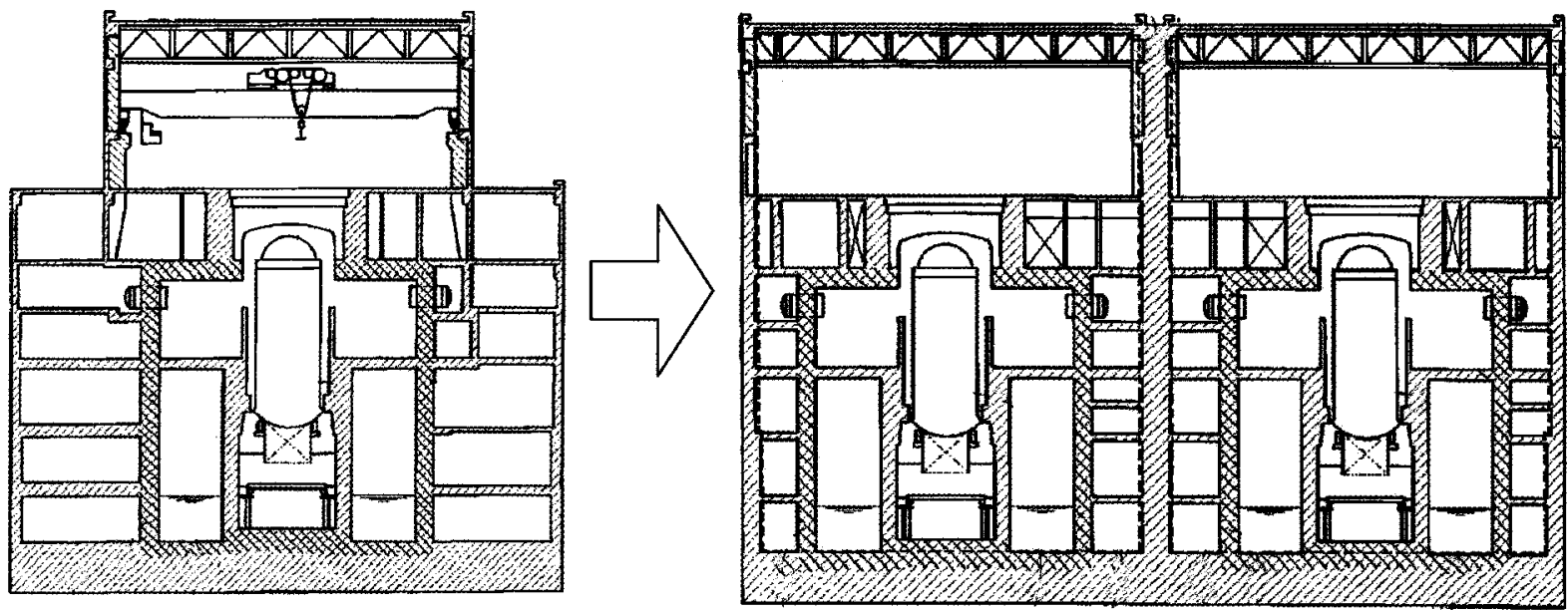

Fig. 1. Concept of NPP [10]

This approach should not only obviate huge redesign and engineering cost as well as investment risk, but also pave the way to cheaper and safer NPPs than equivalent single units of the same electric output. Besides, this technology can potentially be extended to coupling modular reactors as dual, triple, or quadruple units to increase their economic efficiencies, thus accelerating the commercialization as well as the customization of small and medium sized reactors. $[8,9]$

\section{STATE OF THE ART}

The following summarizes two typical prior publications on the subject: one from Japan, and the other from the U.S.

\subsection{Nuclear Power Plant}

The patent, belonging to Toshiba Eng. Co., Ltd. [10], centers on solving the dearth of site areas problem when multiple NPPs are to be installed in a restrained area. The idea is geared to enabling installation of a plurality of nuclear reactors inside a site, to improve safety as well as to reduce the cost of construction by a method wherein the plurality of reactor containers holding a plurality of reactor pressure vessels (RPVs) are held inside a reactor building as demonstrated in Fig. 1.

Inside a virtually columnar reactor building, two secondary containments are held and a central separation wall is provided between them. The reactor containers are provided inside the two secondary containments, and pressure suppression pools are provided inside these containers. Moreover, the RPVs are provided inside the containers, and the reactor cores are held inside the pressure vessels.

Since two nuclear reactors are held in one building in this method, the distance from the building to the boundary

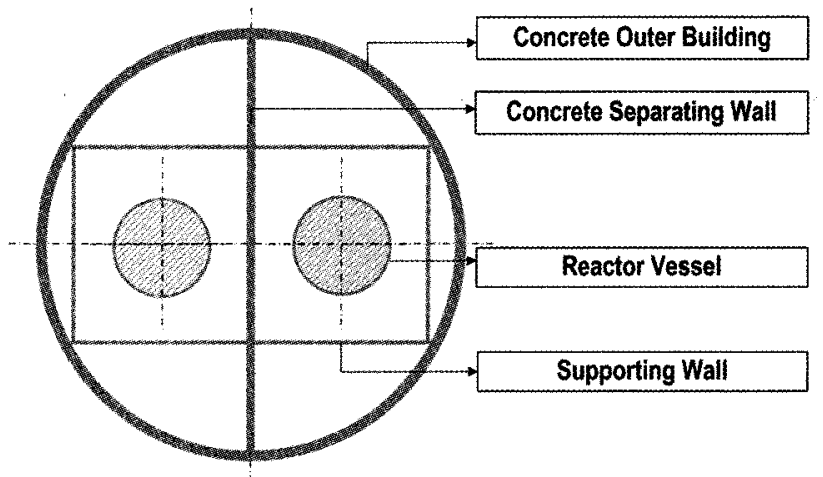

Fig. 2. Schematic Plan View of Double Reactors [10]

of a site can be ensured to be sufficient; it is therefore unnecessary to enlarge the wall thickness of the building so as to enhance the effect of shielding from radiation, and an increase in the weight of the building can be avoided.

Fig. 2 shows the schematic plane of the double reactors. The large outer circle means the concrete outer building; the two rectangles denote the containment building; and the two small inner circles are the reactors. The patent basically covers the boiling water reactor (BWR).

\subsection{Multiple Reactor Containment Building}

The "Multiple Reactor Containment Building" patent of Westinghouse Electric Company LLC [11], aimed at solving a problem similar to that described above, provides three possible prototypes for an NPP.

Fig. 3 illustrates a single containment building including two RPVs having separate coolant systems and separate steam generators (SGs) associated with each of the RPVs.

Fig. 4 provides a single containment building including 


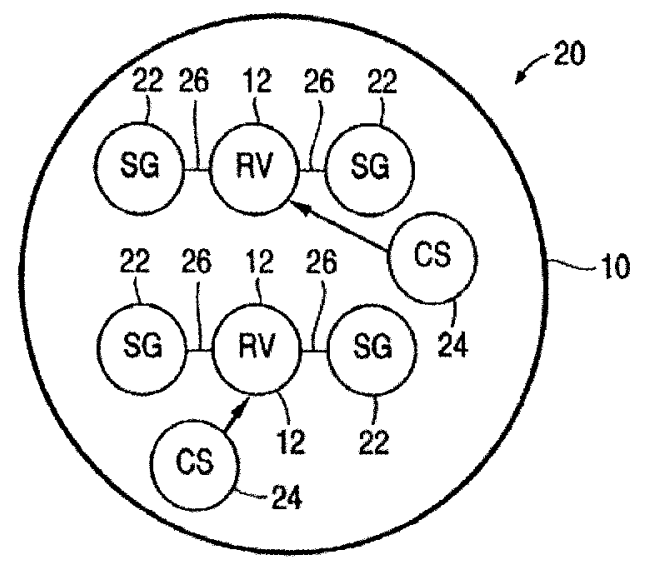

Fig. 3. Scheme of Two Totally Separated NSSSs in a Single Containment [11]

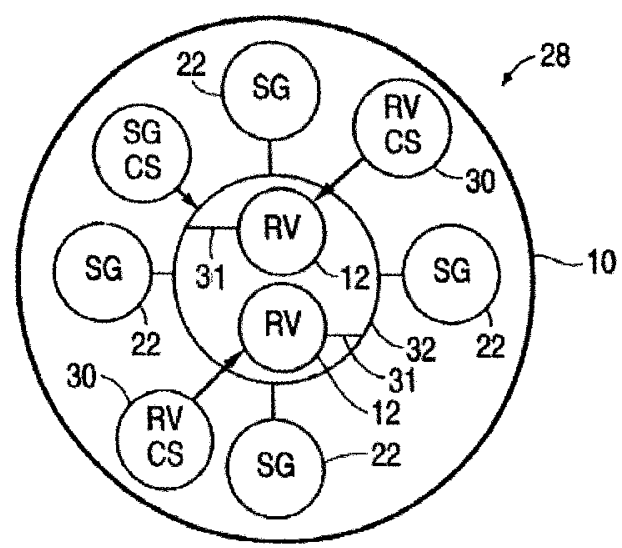

Fig. 4. Scheme of Two NSSSs Shared Feed Water Header in a Single Containment [11]

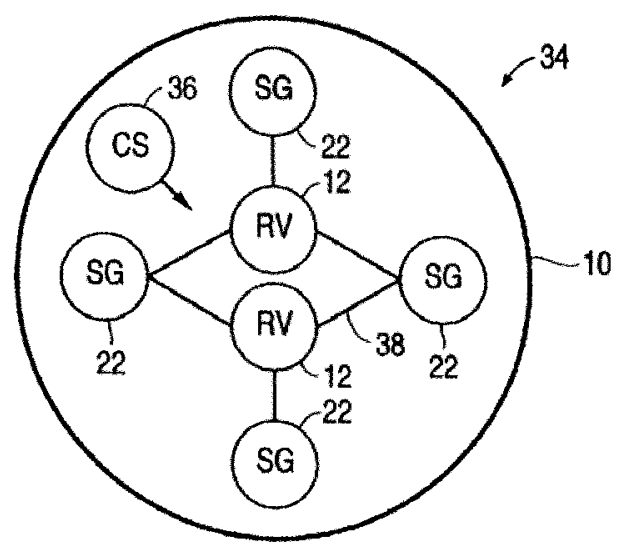

Fig. 5. Scheme of Two United NSSSs in a Single Containment [11] a plurality of RPVs, separate coolant systems, a common feedwater header associated with the separate cooling lines, and a plurality of SGs associated with the common header.

Fig. 5 illustrates a single containment building including a plurality of RPVs, a common coolant system, and common SGs shared between the RPVs.

\section{CHARACTERISTICS OF DU02000}

Construction of DUO2000 is expected to be more economical than building two separate $1000 \mathrm{MWe}$ NPPs in that the construction and maintenance cost of the NPP can be considerably reduced.

First and foremost, the containment, which occupies a large portion in the construction cost, can be reduced. One of the major factors influencing the containment building design and placement is economics, since a containment building is one of the most expensive structures of an NPP. For example, the construction of two APR $1400 \mathrm{~s}$ costs about US $\$ 5$ billion, as shown in Table 1, of which the containment building construction cost is as much as US\$ 0.7 billion [12]. In other words, the containment building costs approximately $14 \%$ of the total installation price for the APR1400. As a result of such expense, it is desirable to maximize the amount of energy generated by such a plant.

Should two or more reactors operate in a single containment building, the containment building would undeniably require significantly less material. For example, when a spherical containment building is used, the revised diameter of the containment building of the NPP, which simply has separated dual reactors, is only approximately $1.2 \sim 1.3$ times the original diameter, as shown in Fig. 6 . The left example in Fig. 6 is a detailed design drawing of the NSSS in the Standard Safety Analysis Report (SSAR) of the APR1400 [14]. The right example in Fig. 6 is a revised cross-section of the containment building of simple dual units like DUO. The DUO approach therefore promises to save more than $6 \%$ of the total NPP construction cost.

Second, the DUO prototype should no doubt contribute to diminution of the construction cost by sharing the safety systems and control systems as well as the NSSS. Connecting the two NSSSs must decrease the number of SGs and reactor coolant pumps (RCPs), and the length of the piping in comparison to constructing two NSSSs. The safety injection system is partly shared. This system provides cooling to prevent core damage and fission product release and ensures adequate shutdown margin. For example, the OPR 1000 safety injection system utilizes four safety injection pumps (SIPs) to inject borated water directly into the RPV and four safety injection tanks (SITs) that can be shared in the DUO2000. In addition, the DUO2000 shares the auxiliary feedwater system to supply feedwater to the SGs for the removal of heat from the reactor coolant 
Table 1. Construction Total Cost and Unit Cost of NPP [13]

\begin{tabular}{|c|c|c|c|}
\hline Project & Reactor & Price & Cost $/ \mathrm{kW}$ \\
\hline EdF Flamanville & EPR & $\begin{array}{l}\text { EUR } 3.3 \text { billion } \\
\text { (US } \$ 4.8 \text { billion) }\end{array}$ & $\begin{array}{l}\text { EUR 2,000 } \\
\text { (US\$2,900) }\end{array}$ \\
\hline $\begin{array}{c}\text { Bruce Power Alberta } \\
2 \times 1,100 \mathrm{MWe}\end{array}$ & ACR & US\$ 6.2 billion & US $\$ 2,800$ \\
\hline $\begin{array}{l}\text { CGNPC Hongyanhe } \\
4 \times 1,080 \mathrm{MWe}\end{array}$ & CPR 1000 & US $\$ 6.6$ billion & US\$ 1,530 \\
\hline $\begin{array}{c}\text { AEO Novovronezh } 6 \& 7 \\
2,136 \mathrm{MWe}\end{array}$ & - & US $\$ 5$ billion & US $\$ 2,340$ \\
\hline $\begin{array}{c}\text { KHNP Shin Korr } 3 \& 4 \\
1,350 \mathrm{MWe}\end{array}$ & APR 1400 & US\$ 5 billion & US\$ 1,850 \\
\hline $\begin{array}{l}\text { FPL Turkey Point } \\
2 \times 1,100 \mathrm{MWe}\end{array}$ & AP1000 & - & $\begin{array}{l}\text { US } \$ 2,444 \\
\sim 3,582\end{array}$ \\
\hline $\begin{array}{c}\text { NEK Belene } \\
2 \times 1,000 \mathrm{MWe}\end{array}$ & AES92 & EUR 3.9 billion & $\begin{array}{l}\text { EUR } 1,950 \\
\sim 3,050\end{array}$ \\
\hline UK composite projection & - & - & US $\$ 2,400$ \\
\hline $\begin{array}{l}\text { NRG South Texas } \\
2 \times 1,350 \mathrm{MWe}\end{array}$ & ABWR & US $\$ 8$ billion & US $\$ 2,900$ \\
\hline
\end{tabular}

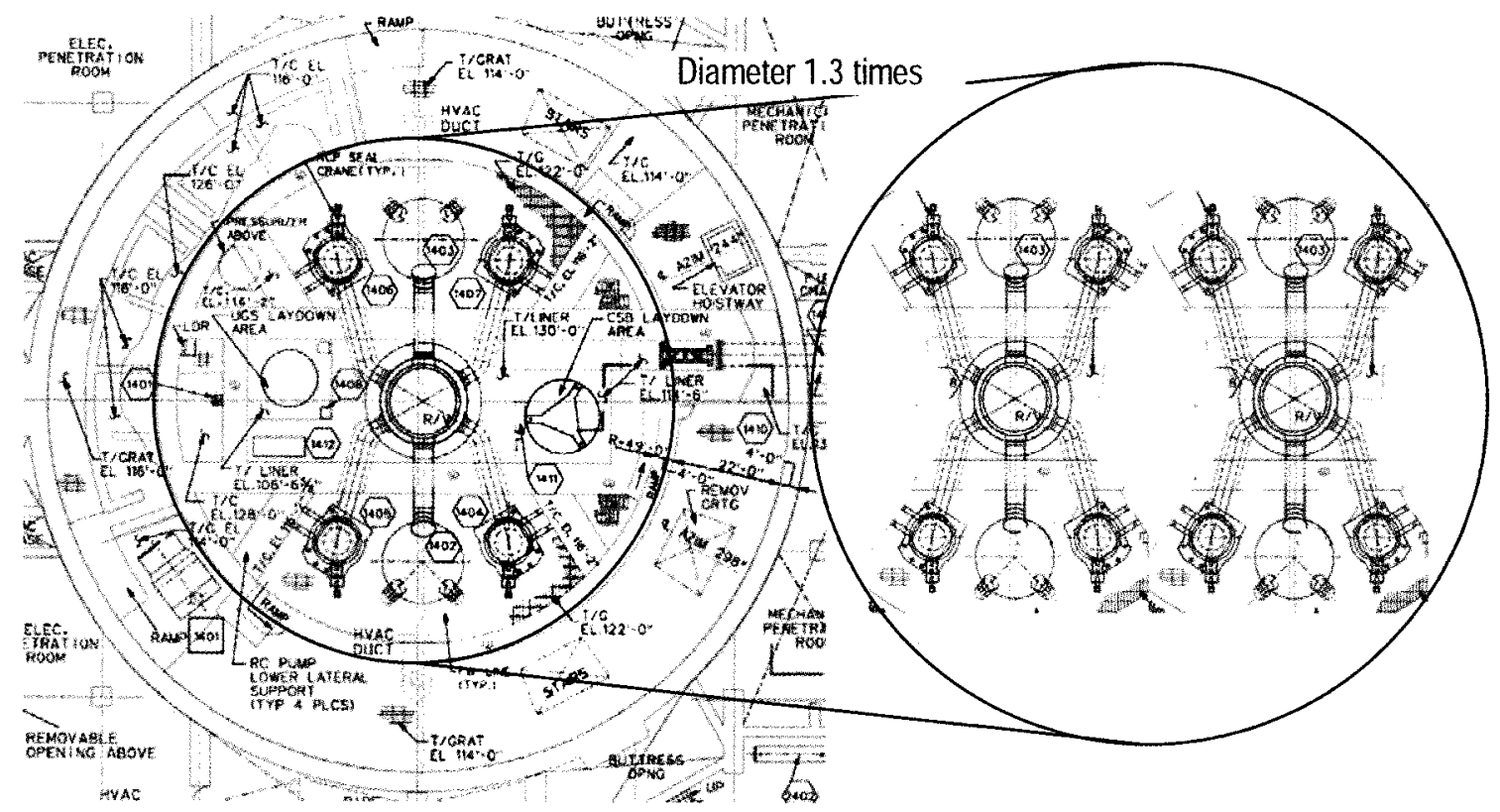

Fig. 6. Footprint of Containment Including Two NSSSs

system (RCS) in the event that the main feedwater system is unavailable following a transient or accident, and shares heating, ventilating, and air conditioning (HVAC) systems designed for personnel comfort and equipment operation.

Last, but certainly not least, the maintenance cost can be palpably cut in the DUO, in particular the management 
Table 2. Different Characteristics of DUO2000 Prototypes

\begin{tabular}{c|c|c|c}
\hline Prototype & Connecting reactors & Connecting scheme & Limitation \\
\hline 1 & 2 loop reactors & Totally separated NSSSs & - \\
\hline 2 & 2 loop reactors & Shared one large SG & Nonuniform SGs \\
\hline 3 & 2 loop reactors & Using cross pipes & Complex piping \\
\hline 4 & 3 loop reactors & Shared 1 large SG & Nonuniform SGs \\
\hline 5 & 4 loop reactors & Shared 2 large SG & Nonuniform SGs \\
\hline
\end{tabular}

Table 3. Number of NSSS Components of Each of DUO2000 Prototypes

\begin{tabular}{c|c|c|c|c|c|c}
\hline Prototype & NSSS & Loop & Reactors & SG & RCP & Reference \\
\hline 1 & Totally separated & 4 & 2 & Uniform sized 4 & 8 & Fig. 8 \\
\hline 2 & United & 3 & 2 & 1 big, 2 small & 6 & Figs. $9 \& 10$ \\
\hline 3 & United & 3 & 2 & Uniform sized 4 & 8 & Figs. $11 \& 12$ \\
\hline 4 & United & 5 & 2 & 1 big, 4 small & 6 & Figs. $13 \& 14$ \\
\hline 5 & United & 4 & 2 & 2 big, 4 small & 8 & Figs. $15 \& 16$ \\
\hline
\end{tabular}

part of the NPP. All the control systems can be managed as one except for the reactor control, because the two NSSSs are united into one. Thus, the cost of manpower and equipment can be dramatically reduced.

Moreover, DUO is more advantageous in satisfying the safety design criteria. Representatively, the coolant inventory of a united NSSS is almost twice as much as that of one NSSS. Large coolant inventory in the NSSS results in large thermal inertia and long response time in the case of transients or accidents. In particular, the negative effect of loss of coolant can be reduced, as it belongs to the safety design features, defense in depth level 2 - control of abnormal operation and detection of failure.

\section{PROTOTYPES OF DUO2000}

Five prototypes of the DUO are suggested as summarized in Table 2. Albeit each of the five prototypes has advantages and downsides of its own, all share a connection of two $1000 \mathrm{MWe}$ reactors such as OPR 1000.

Prototype 1 has a single containment building including two RPVs having separate coolant systems and separate SGs associated with each of the RPVs. Prototype 2 has a single containment building including two RPVs having a common coolant system and a common SG shared between the RPVs. The capacity of the common $\mathrm{SG}$ is twice as much as those of the other two SGs outside the two RPVs. Prototype 3 has a single containment building including two RPVs having a common coolant system as well. However, prototype 3 does not have a common SG between the RPVs, but has cross piping between RPVs to

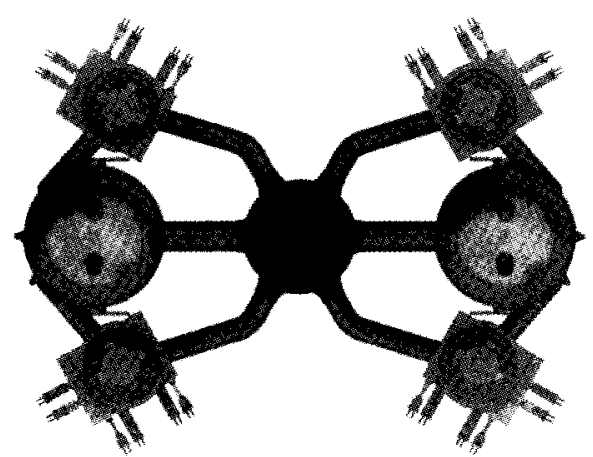

Fig. 7. Top View of 3D Model of OPR 1000 
share the coolant system. Prototypes 4 and 5 are almost the same as prototype 2 in the way of connecting the primary coolant systems. But prototype 4 connects the 3 loop reactor system such as those of Ulchin Units 1 and 2 of the Framatome design. Prototype 5 attaches the 4 loop reactor system such as the EPR. The common $\mathrm{SG}$ of prototypes $4 \& 5$ can be modified as cross piping to couple the two coolant systems.

Table 3 lists the number of loops and compartments in the primary coolant system of prototypes.

The original reactor systems of prototypes 1 and 2 before connection are based on OPR 1000. Fig. 7 illustrates the three-dimensional (3D) models of the OPR 1000.

\subsection{Prototype 1}

DUO2000 prototype 1 has two RPVs that have totally separate primary coolant systems in a single containment. It is possible to reduce the construction cost of the containment building since the two reactors are in a single containment. Also, this prototype is simple to apply because there is no difference in NSSS from the original model, OPR 1000. Thermal hydraulic design characteristics are not changed. Fig. 8 illustrates the top view of the DUO2000 prototype 1, which has a total of 4 loops, 2 RPVs, 4 SGs and $8 \mathrm{RCPS}$.

\subsection{Prototype 2}

DUO2000 prototype 2 has a single NSSS consisting of two RPVs in a single containment building. The two RPVs have a common coolant system and a common SG

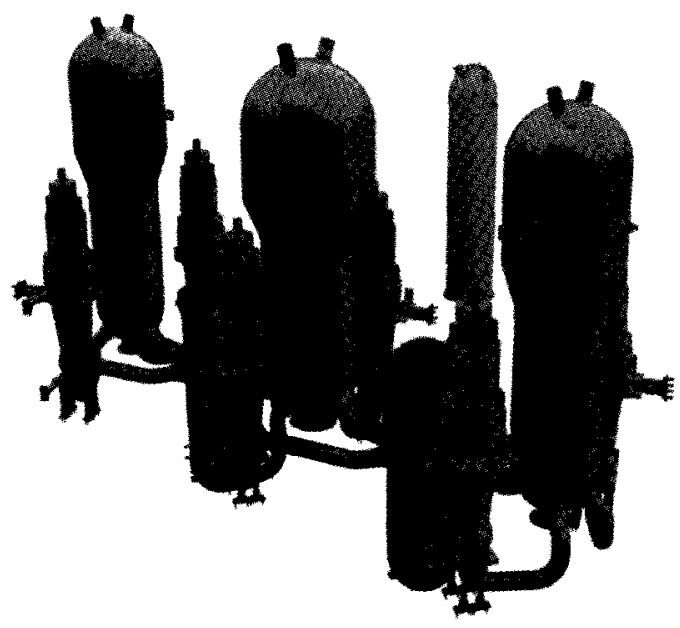

Fig. 10. Bird's-Eye View of Prototype 2

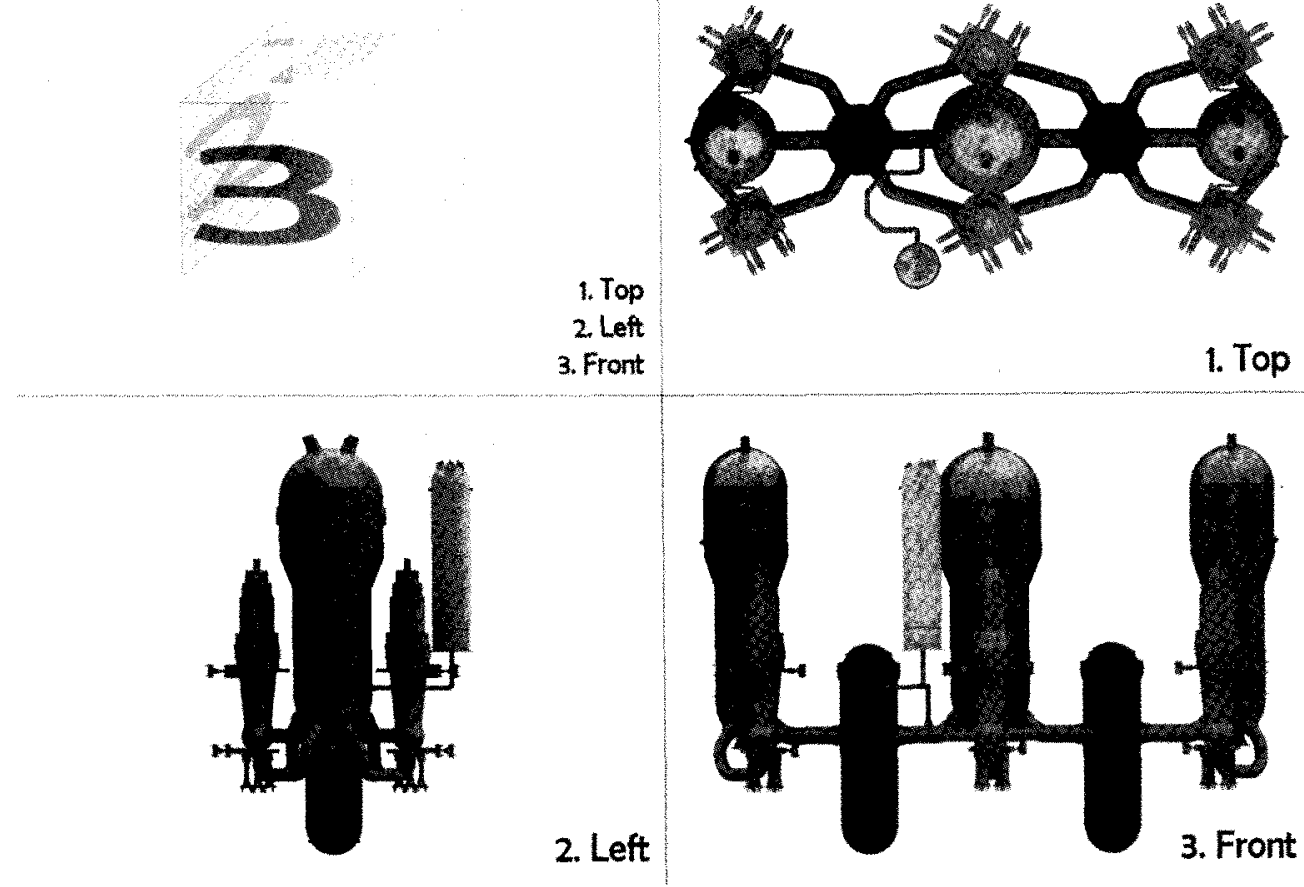

Fig. 9. Top, Side, and Front Views of Prototype 2 


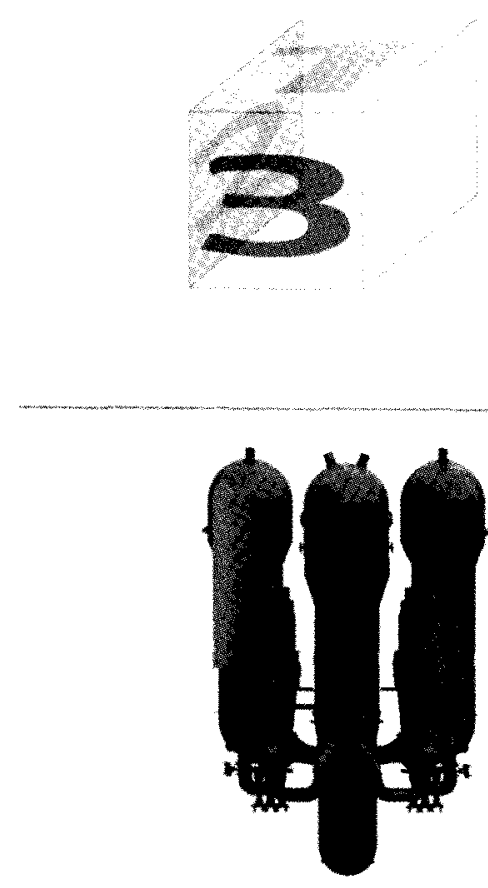

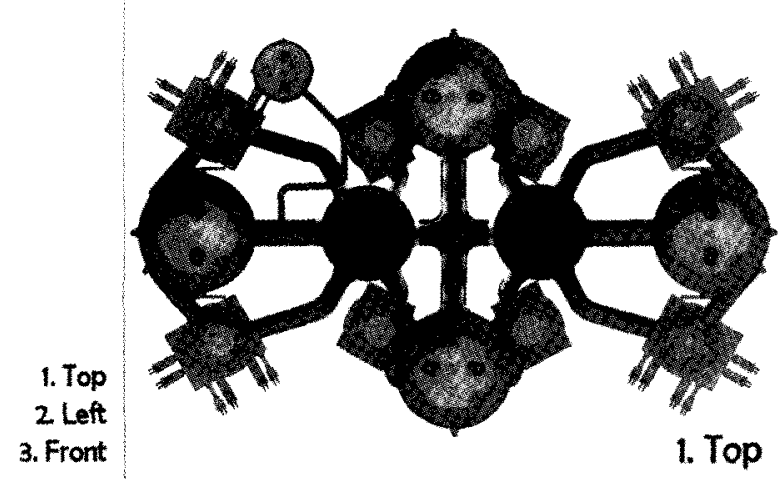

2. Left

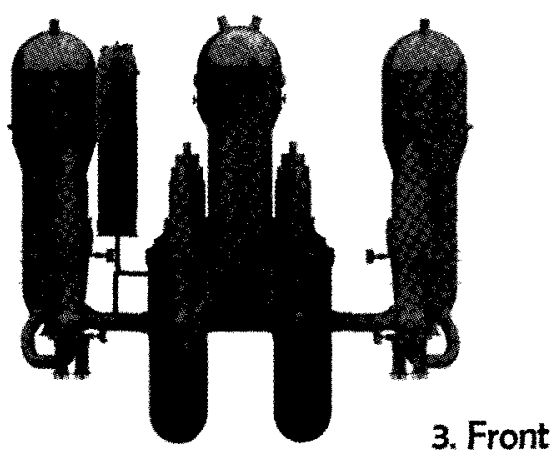

Fig. 11. Top, Side, and Front View of Prototype 3

shared between the RPVs. The capacity of the common $\mathrm{SG}$ is twice as much as that of the other two SGs outside of the two RPVs. The common SG abates the complexity of piping. However, though it is possible to increase the capacity of the SG by increasing the number of $U$ tubes, the SGs are not uniform. Nonuniform SGs can increase the total cost of construction. This model connects the two OPR $1000 \mathrm{~s}$ and has two hot legs and two loops. Fig. 9 provides the top, side and front views. Prototype 2 has a total of 3 loops, 2 RPVs, 3 SGs and 6 RCPs; its bird'seye view is shown in Fig. 10.

\subsection{Prototype 3}

Prototype 3 carries a single NSSS composed of two RPVs in a single containment building. It has cross piping between RPVs to share the coolant system. The cross piping receives the hot coolant from two reactors and provides the coolant to two SGs by diverging it. Two RPVs share the coolant system and two SGs between the RPVs. The capacities of the common SGs and of the outside SGs are identical. Although it is true that this prototype aggravates the complexity of piping and augments the hydraulic resistance of the primary coolant system, it unifies the size of SGs. It connects the two OPR 1000 s that have two hot legs and two loops. Fig. 11 illustrates the top, side, and front views of prototype 3 with a total

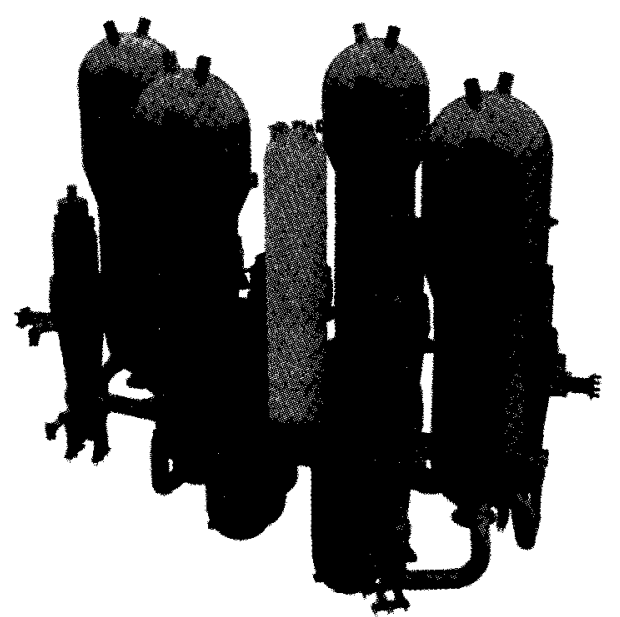

Fig. 12. Bird's-Eye View of Prototype 3

of 3 loops, 2 RPVs, 4 SGs, and 8 RCPs; its bird's-eye view is shown in Fig. 12.

\subsection{Prototype 4}

Prototype 4 is home to a single NSSS comprising two RPVS in a single containment building. The two RPVS 

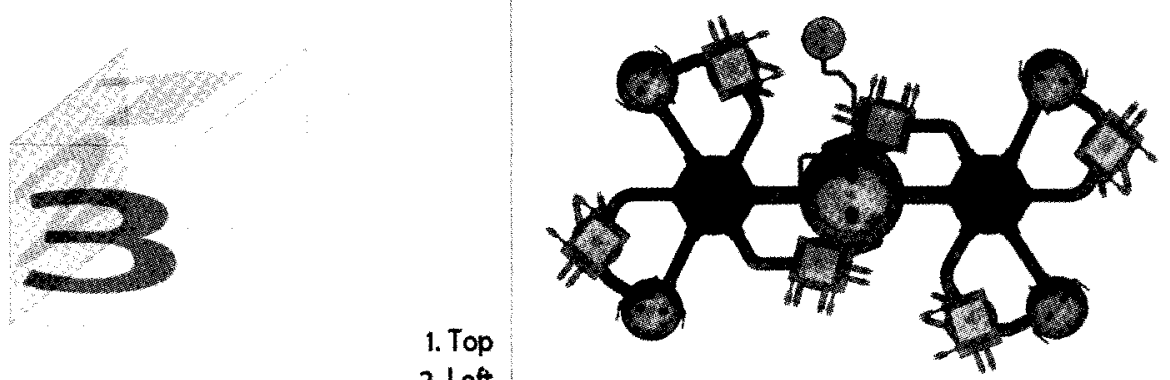

2 Left

3. Front

1. Top

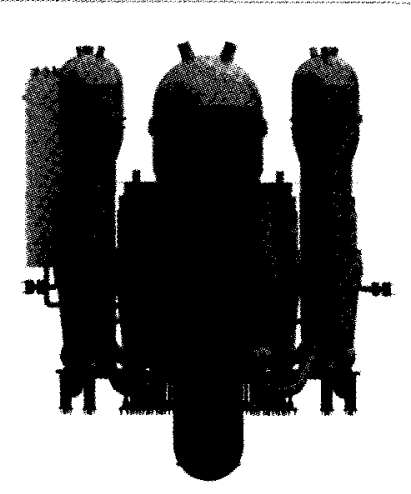

2. Left

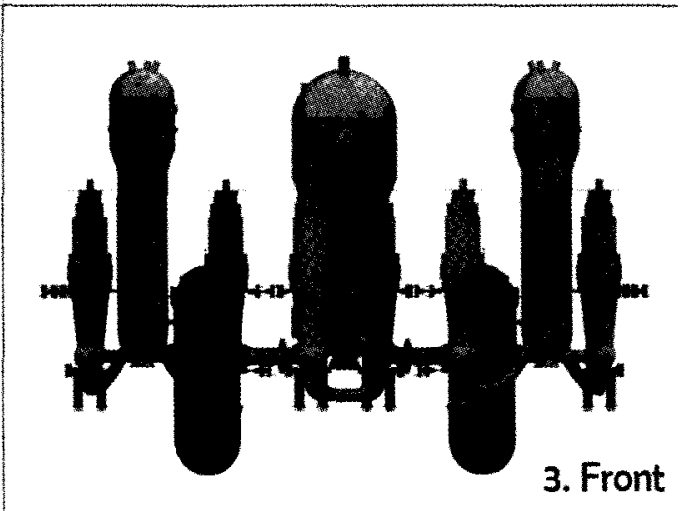

Fig. 13. Top, Side, and Front Views of Prototype 4

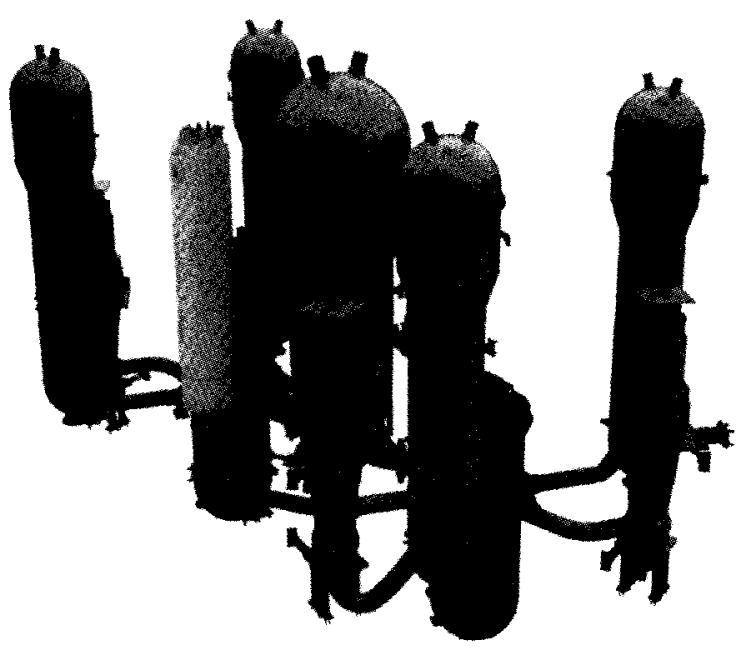

Fig. 14. Bird's-Eye View of Prototype 4

have a common coolant system and a common SG shared between the RPVs. The capacity of the common SG is twice as much as that of the other four SGs outside the two RPVs. The common SG abates the complexity of piping. However, although it is possible to increase the capacity of the SG by increasing the number of $U$ tubes, the size of the SG is not uniform. Nonuniform SGs may potentially lead to an increase in the total cost of construction. This model connects two $1000 \mathrm{MWe}$ reactors that have three hot legs and three loops. Each reactor design is based on those of Ulchin Units 1 and 2, whose design is of Framatome. Since each reactor has three hot legs, it is possible to share two SGs. In this case, the total number of SGs is four, housing two large SGs and two small SGs. Moreover, cross pipe is also utilized as was the case with prototype 2. Fig. 13 illustrates the top, side and front views of prototype 4, having a total of 5 loops, 2 RPVs, 5 SGs, and 6 RCPs, with its bird's-eye view in Fig. 14.

\subsection{Prototype 5}

Prototype 5 has a single NSSS composed of two RPVs in a single containment building. The two RPVs have a common coolant system and a common SG shared between the RPVs. The capacity of the common SG is twice those of the other four SGs outside the two RPVs. The common SG abates the complexity of piping. However, although it is possible to increase capacity of the SG by increasing number of U tubes, the SGs are not uniform. Nonuniform SGs may add to the total cost of construction. This model connects two $1000 \mathrm{MWe}$ reactors that have four hot legs and three loops, respectively. Each reactor design is similar 

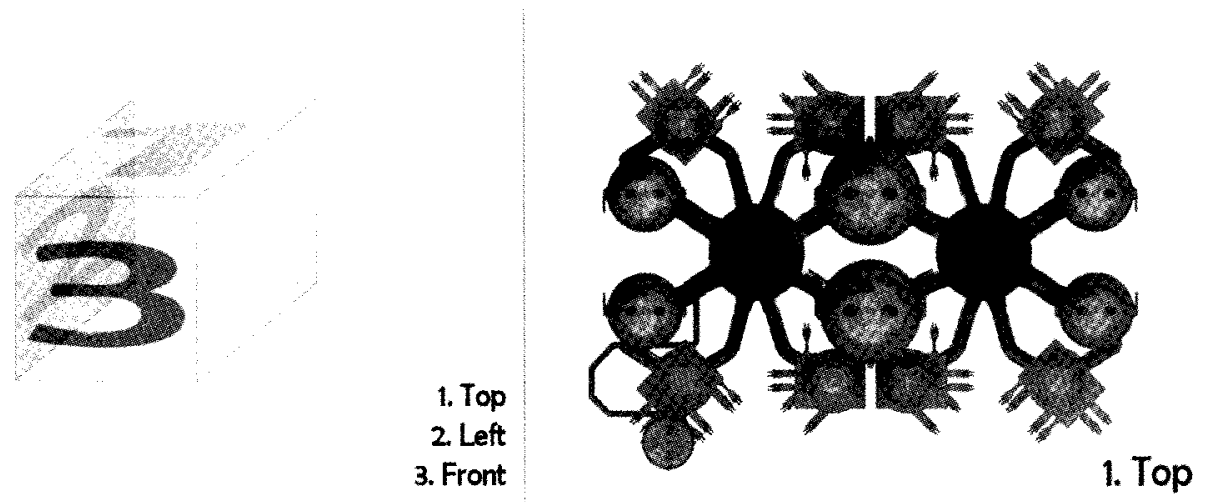

2. Left

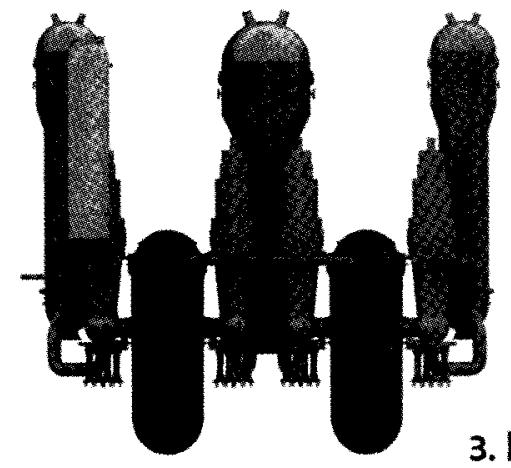

\section{Front}

Fig. 15. Top, Side, and Front Views of Prototype 5

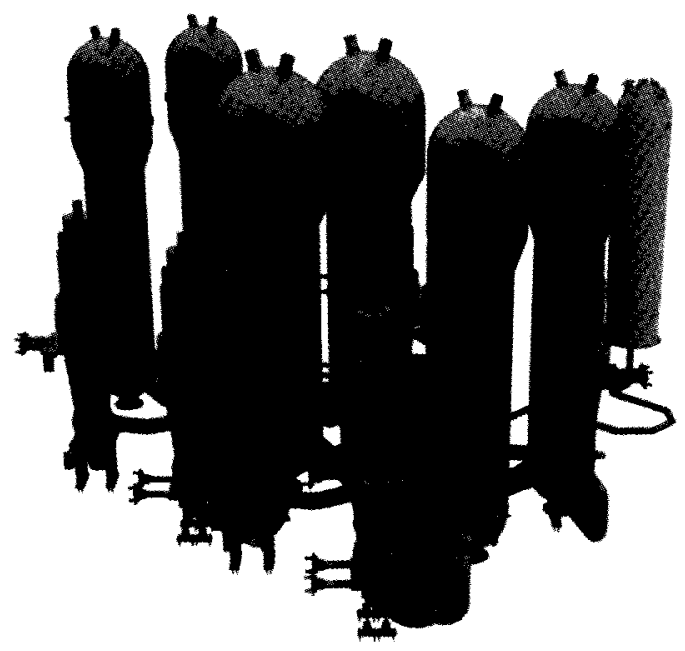

Fig. 16. Bird's-Eye View of Prototype 5

to that of the EPR of AREVA, having four loops. Cross pipe is also utilized as was the case in prototype 2. Fig. 15 demonstrates the top, side, and front views of prototype 5 with a total of 5 loops, 2 RPVs, 5 SGs, and 6 RCPs, with their bird's-eye view in Fig. 16.

\section{ENGINEERING OF DU02000}

Table 4 summarizes the areas of direct import from the OPR1000 design versus those requiring further development to meet the DUO2000 safety design standard.

Note that design modifications are required of the reactor coolant system and connected systems and auxiliary systems, and steam and power conversion system to start with. Whereas the aforementioned systems are to be adjusted in DUO2000, each component in these systems may safely be utilized per se. The engineered safety features have four branches. The first is the containment system. The volume of containment is expanded by combining two NSSSs so that the capability of each part of this system must as well be augmented. The second is the safety depressurization and vent system, and the incontainment water storage system which can be the same as those of OPR 1000 . The third is the safety injection system. This system may as well be directly taken from the OPR1000, but had better be altered to accommodate for the DUO2000 configuration.

Last, but certainly not least, accident analysis has definitely to be replenished. For instance, decrease in the reactor coolant flow rate and decrease in the RCS inventory will be totally different from those of OPR 1000 since the RCS inventory of the DUO2000 shall be close to twice 
Table 4. Summary of DUO2000 Safety Design Engineering

\begin{tabular}{c|c}
\hline Direct import from OPR1000 & Additional development over OPR1000 \\
\hline Site envelope characteristics & Reactor coolant system and connected systems \\
\hline Reactors & Engineered safety features \\
\hline Instrument and controls & Auxiliary systems \\
\hline Electric power & Steam and power conversion system \\
\hline Conduct of operations & Accident analysis \\
\hline Human factor engineering & Probabilistic safety assessment \\
\hline Radioactive waste management & Radiation protection \\
\hline
\end{tabular}

that of the OPR1000. Increase in heat removal by the secondary system will have to be reconsidered. As the two RPVs are adjacent, radiation protection must be carefully reexamined.

\section{SUMMARY}

Prototypes 2 and 3 appear to be the most promising of the DUO2000, because these two prototypes are not only based on the OPR 1000, which has been proven for a number of reactor years, but also have relatively simple design and applicability.

Albeit cross piping may slightly reduce the efficiency of NSSS due to complex piping, since nonuniform SGs increase the total cost of construction to offset the disadvantage of prototype 2 , prototype 3 is considered to surpass prototype 2 .

Prototypes 4 and 5 may prove to be more operationally stable since the capacity of each of the SGs is small enough not to bring about problems when joining them.

Further work is in progress. The first challenge is with the number and location of the pressurizers. Since the system is being expanded, one pressurizer may not be enough to maintain the pressure. The pressure in the loop between reactors may tend to differ from that in the outside loop. The second concern is the unbalanced piping, which may potentially put the safety of the NSSS in jeopardy. Overall safety analysis has yet to be done to check on the reactor coolant system, engineered safety features, transient asymmetric system response to abnormal events and accidents, core damage frequency, and large early release from the containment. Particular attention needs to be paid to the structural integrity of the NSSS and the containment building, including the seismic response of these structures.

Once fully developed and demonstrated, the proposed DUO technology shall certainly be deployed on a commercial scale. DUO for other commercial large scale reactors may become available, enabling enormous curtailing of the construction cost of Generation III+ systems. Moreover, this technology can pave the way for the coupling of modular reactors as dual, triple, or quadruple units to increase their economic efficiencies, and thus accelerate the commercialization, as well as the customization, of small and medium sized reactors.

\section{ACKNOWLEDGMENTS}

This work was performed under the auspices of the Brain Korea 21 Energy Systems Engineering Program at Seoul National University awarded by the Korean Ministry of Education, Science \& Technology.

\section{REFERENCES}

[ 1 ] http://www.ap1000.westinghousenuclear.com/

[2] http://www.opr1000.com/

[3] http://www.apr1400.com

[4] http://us.areva.com

[5] http://www.mhi.co.jp/en/

[6] J.L. REMPE, K.Y. Suh, F.B. Cheung and S.B. Kim, "InVessel Retention of Molten Corium- Lessons Learned and Outstanding Issues," Nuclear Technology, Vol. 161, pp. 210-267, March (2008).

[7] J. YANG, F.B. Cheung, J.L. Rempe, K.Y. Suh and S.B. Kim, "Critical Heat Flux for Downward-Facing Boiling on a Coated Hemispherical Vessel Surrounded by an Insulation Structure," Nuclear Engineering \& Technology, Vol. 38 (2), pp. 139-146, February (2006).

[8] http://www.babcock.com/products/modular_nuclear/

[9] IAEA, "Design Features to Achieve Defense in Depth in Small and Medium Sized Reactors," Nuclear Energy Series No. NP-T-2.2, June (2009)

[10] T. SADAHIKO, "Nuclear Power Plant," Patent No. 3739868 , Japan Patent, November 11 (2005).

[11] K.R. ROHDE and J.L. Ford, "Multiple Reactor Containment Building," Patent No. 6327323, U.S. Patent, December 4 (2001).

[12] Korea Hydro \& Nuclear Power Co., Ltd., "Public Notice of Tendering Procedure for Construction Works of the ShinUlchin Nuclear Power Plant Units 1 \& 2 (APR1400 $\times 2$ Units),"July 1 (2009).

[13] World Nuclear Association, "The Economics of Nuclear Power," November (2008).

[14] Korea Electric Power Corp., "Advanced Power Reactor 1400 MWe Standard Safety Analysis Report," Seoul Korea (2001). 